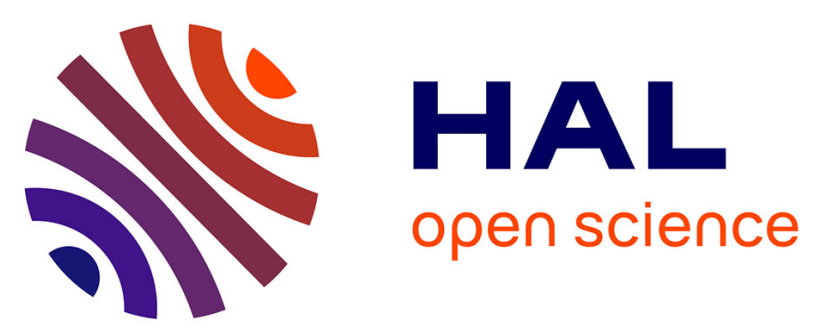

\title{
Binding of the five multistate species of the anthocyanin analog 7- $\beta$-D-glucopyranosyloxy-4'-hydroxyflavylium to the $\beta$-cyclodextrin derivative captisol
}

Johan Mendoza, Nuno Basílio, Olivier Dangles, Nathalie Mora, Sheiraz Al Bittar, Fernando Pina

\section{To cite this version:}

Johan Mendoza, Nuno Basílio, Olivier Dangles, Nathalie Mora, Sheiraz Al Bittar, et al.. Binding of the five multistate species of the anthocyanin analog $7-\beta$-D-glucopyranosyloxy-4'hydroxyflavylium to the $\beta$-cyclodextrin derivative captisol. Dyes and Pigments, 2017, 143, pp.479-487. 10.1016/j.dyepig.2017.04.061 . hal-01552150

\section{HAL Id: hal-01552150 \\ https://hal.science/hal-01552150}

Submitted on 30 Jun 2017

HAL is a multi-disciplinary open access archive for the deposit and dissemination of scientific research documents, whether they are published or not. The documents may come from teaching and research institutions in France or abroad, or from public or private research centers.
L'archive ouverte pluridisciplinaire HAL, est destinée au dépôt et à la diffusion de documents scientifiques de niveau recherche, publiés ou non, émanant des établissements d'enseignement et de recherche français ou étrangers, des laboratoires publics ou privés.

\section{다(1)(2)}

Distributed under a Creative Commons Attribution - ShareAlikel 4.0 International 


\title{
Binding of the five multistate species of the anthocyanin analog $7-\beta$-D-glucopyranosyloxy-4'-hydroxyflavylium to the $\beta$-cyclodextrin derivative captisol
}

\author{
Johan Mendoza a , Nuno Basílio ${ }^{\mathrm{a}}$, Olivier Dangles ${ }^{\mathrm{b}}{ }^{* *}$, Nathalie Mora ${ }^{\mathrm{b}}$, Sheiraz Al Bittar ${ }^{\mathrm{b}}$, \\ Fernando Pina ${ }^{\mathrm{a}, *}$ \\ a LAQV-REQUIMTE, Department of Chemistry, Faculty of Science \& Technology, Universidade NOVA de Lisboa, 2829-516, Monte de Caparica, Portugal \\ ${ }^{\mathrm{b}}$ University of Avignon, INRA, UMR408, 84000, Avignon, France
}

Keywords:

Anthocyanin

Flavylium

Cyclodextrin

Host-guest

Multistate

\begin{abstract}
A B S T R A C T
The host-guest chemistry of the anthocyanin analog 7- $\beta$-D-glucopyranosyloxy-4'-hydroxyflavylium (GHF) was studied in the presence of the $\beta$-cyclodextrin derivative captisol by stopped flow, UV-visible spectroscopy, flash photolysis, circular dichroism and isothermal titration calorimetry. The equilibrium and rate constants of the multistate of chemical species derived from the flavylium ion were calculated and compared with those in the absence of the host. A new procedure to obtain the host-guest association constants of the multistate (including the transient species) by superimposing the two energy level diagrams, in the presence and absence of the cyclodextrin, was developed. The results indicate that the magnitude of the association constants follows the order, trans-chalcone $\approx$ cischalcone $\approx$ hemiketal $>$ quinoidal base $>$ flavylium cation. The hydration equilibrium constant increases ca. 42 times in the presence of captisol as the hydration and dehydration rate constants respectively increases and decreases. The other equilibrium constants are modestly affected: the rate constants of ring closure and opening are significantly decreased in the complex and the isomerization rate constants increase in both directions. The quantum yield of the photochromic system in the presence of captisol is 0.3 , i.e. 3 times higher than in the absence of the host.
\end{abstract}

\section{Introduction}

The flavylium cation is a common feature of natural pigments, such as anthocyanins and 3-deoxyanthocyanins, and many other synthetic dyes including styrylflavylium and napthoflavylium ions. However, the flavylium cation $\left(\mathbf{A H}^{+}\right)$is only one of the species of a more general multistate of chemical species, reversibly interconverted by external stimuli, such as $\mathrm{pH}$ modifications and light [1-3]. The flavylium cation is generally the stable species of the multistate in a narrow and very acidic $\mathrm{pH}$ window. Upon raising the $\mathrm{pH}$ to moderately acidic/neutral solutions, four other different species are formed according to the sequence, quinoidal base $(\mathbf{A})$, hemiketal (B), cis-chalcone (Cc) and trans-chalcone (Ct) (Scheme 1).

\footnotetext{
* Corresponding author.

** Corresponding author.

E-mail addresses: olivier.dangles@univ-avignon.fr (O. Dangles), fp@fct.unl.pt (F. Pina).
}

The chemical reactions reported in Scheme 1 are accounted for by Eq. (1)-(4)

$$
\begin{aligned}
& \mathbf{A H}^{+}+\mathrm{H}_{2} \mathrm{O} \rightleftharpoons \mathbf{A}+\mathrm{H}_{3} \mathrm{O}^{+} \quad K_{\mathrm{a}} \text { acid-base } \\
& \mathbf{A H}^{+}+2 \mathrm{H}_{2} \mathrm{O} \rightleftharpoons \mathbf{B}+\mathrm{H}_{3} \mathrm{O}^{+} \quad K_{\mathrm{h}} \text { hydration } \\
& \mathbf{B} \rightleftharpoons \mathbf{C c} \quad K_{\mathrm{t}} \quad \text { tautomerization } \\
& \mathbf{C c} \rightleftharpoons \mathbf{C t} \quad K_{\mathrm{i}} \quad \text { isomerization }
\end{aligned}
$$

The addition of base to equilibrated acidic solutions of the flavylium cation is defined here as the direct $\mathrm{pH}$ jump. After a direct $\mathrm{pH}$ jump, two competitive reactions take place, proton transfer, Eq. (1), leading to the quinoidal base, and hydration, Eq. (2), leading to the hemiketal. Proton transfer is by far the faster reaction of the multistate ( $\mu$ s timescale) and thus the first species to be formed is the quinoidal base. Flavylium cation and quinoidal base are 


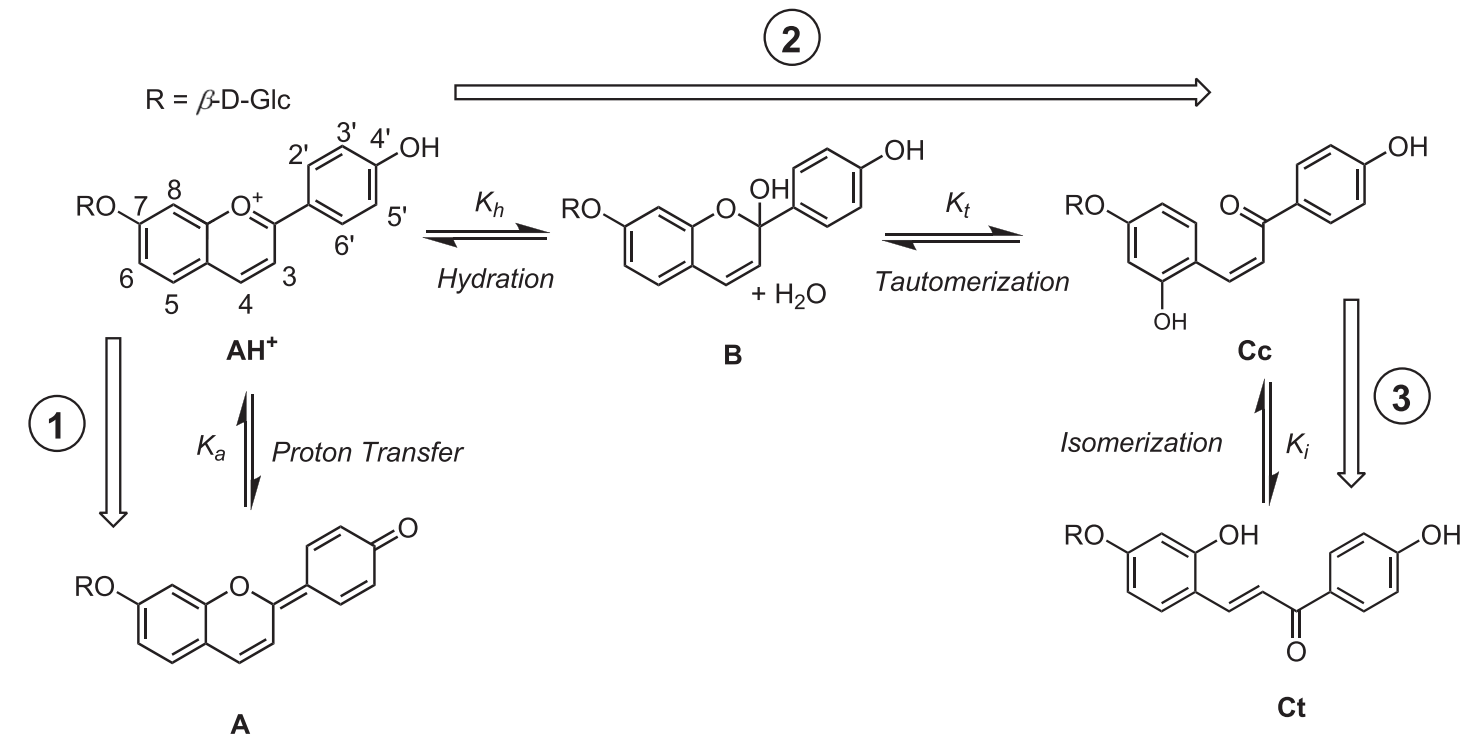

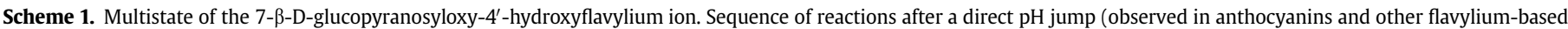

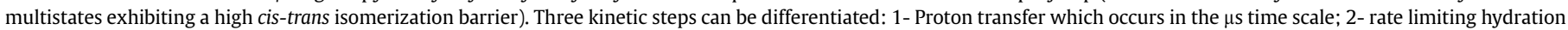
(seconds-minutes time scale) followed by fast and therefore kinetically silent tautomerization and 3-slow isomerization in the hours time scale.

maintained in fast equilibrium during all the next kinetic steps and behave as a single species. When there is a cis-trans isomerization barrier as for anthocyanins and the present compound, the isomerization is the slowest kinetic step. Except in very acidic medium, the hydration (timescale of seconds-minutes) is slower than tautomerization (ms timescale) [4,5]. This behavior leads in general to three well separated kinetic processes: 1- equilibrium between flavylium cation and quinoidal base (only accessed by very fast techniques such as temperature jumps and in some favorable cases by flash photolysis); 2- formation of hemiketal through the hydration reaction (rate-determining step) followed by a faster tautomerization yielding the cis-chalcone; 3 -isomerization, Scheme 1.

The three kinetic steps can be accounted for by Eq. (5)-(7) [6].

$k_{1 s t}=k_{a}+k_{-a}\left[H^{+}\right]$

$k_{2 n d}=\frac{\left[H^{+}\right]}{\left[H^{+}\right]+K_{a}} k_{h}+\frac{1}{1+K_{t}} k_{-h}\left[H^{+}\right]$

$k_{3 t h}=\frac{K_{h} K_{t}}{\left[H^{+}\right]+K_{a}+K_{h}+K_{h} K_{t}} k_{i}+k_{-i}$

When the system reaches the equilibrium, the mole fraction distribution of the species is dependent on $\mathrm{pH}$ and can be expressed by a simple acid-base reaction involving the flavylium cation $\left(\mathbf{A H}^{+}\right)$ and an apparent conjugated base $\mathbf{C B}$ defined as the sum of the concentrations of quinoidal base $(\mathbf{A})$, hemiketal (B) cis-chalcone (Cc) and trans-chalcone (Ct), Eq. (8)

$\mathbf{A H}^{+}+\mathrm{H}_{2} \mathrm{O} \rightleftharpoons \mathbf{C B}+\mathrm{H}_{3} \mathrm{O}^{+} \quad K_{\mathrm{a}}^{\prime}$

$[\mathbf{C B}]=[\mathbf{A}]+[\mathbf{B}]+[\mathbf{C c}]+[\mathbf{C t}]$

$K^{\prime}{ }_{a}=K_{a}+K_{h}+K_{h} K_{t}+K_{h} K_{t} K_{i}$

Due to the fact that the isomerization is much slower than the other kinetic steps, it is possible to define a pseudo-equilibrium, i.e. a transient state where the species $\mathbf{A H}^{+}, \mathbf{A}, \mathbf{B}$ and $\mathbf{C c}$ can be considered in equilibrium before formation of significant amounts of Ct, Eq. (10).

$$
\begin{aligned}
& \mathbf{A H}^{+}+\mathrm{H}_{2} \mathrm{O} \rightleftharpoons \mathbf{C B}+\mathrm{H}_{3} \mathrm{O}^{+} \quad \hat{K_{\mathrm{a}}} \\
& {[\mathbf{C B}]=[\mathbf{A}]+[\mathbf{B}]+[\mathbf{C c}]} \\
& K_{a}=K_{a}+K_{h}+K_{h} K_{t}
\end{aligned}
$$

The flavylium-based multistate can be also studied carrying out reverse $\mathrm{pH}$ jumps, defined as the addition of acid to equilibrated solutions of $\mathbf{C B}$, or $\mathbf{C B}$. If the final $\mathrm{pH}$ is sufficiently low, dehydration becomes faster than tautomerization and four distinct steps can be observed: i) conversion of the quinoidal base into flavylium cation during the mixing time of the stopped flow device, ii) dehydration of the hemiketal into flavylium cation, Eq. (12), iii) a slower step due to the conversion of the cis-chalcone into flavylium cation via the hemiketal, Eq. (13), iv) when the initial state is the equilibrium (CB), conversion of trans-chalcone into flavylium cation in a much slower process, Eq. (7). When these experiments are carried out from the pseudo-equilibrium step iv) is not observed. In Eq. (13) the acidic and basic catalysis is considered [3].

$k_{1 s t \text { reverse }}=\frac{\left[\mathrm{H}^{+}\right]}{\left[\mathrm{H}^{+}\right]+K_{a}} k_{h}+k_{-h}\left[H^{+}\right]$

$k_{2 n d \text { reverse }}=k_{-t}+k_{-t}^{H}\left[H^{+}\right]+k_{-t}^{\mathrm{OH}}\left[\mathrm{OH}^{-}\right]$

A very useful way to rationalize the flavylium multistate is the construction of an energy level diagram based on the equilibrium constants. The different species of the multistate are positioned in the diagram and only the energy level of the flavylium cation depends on $\mathrm{pH}$, Scheme 2 [7].

Many external factors affect directly the equilibrium between flavylium species, and their stability is an important property. $\mathrm{Cy}$ clodextrins, as cyclic hosts, have been tested to improve the stability of different dyes by means of encapsulation procedures [8-10]. Particularly, highly water-soluble polyanionic $\beta$-cyclodextrin derivatives bearing sulfobutyl chains, captisol [11], has been used to increase the stability and water-solubility of organic dyes, such as curcuminoids [12,13], carotenoids [14,15], and flavonoids $[16,17]$. In this work, we describe a new procedure based on the 


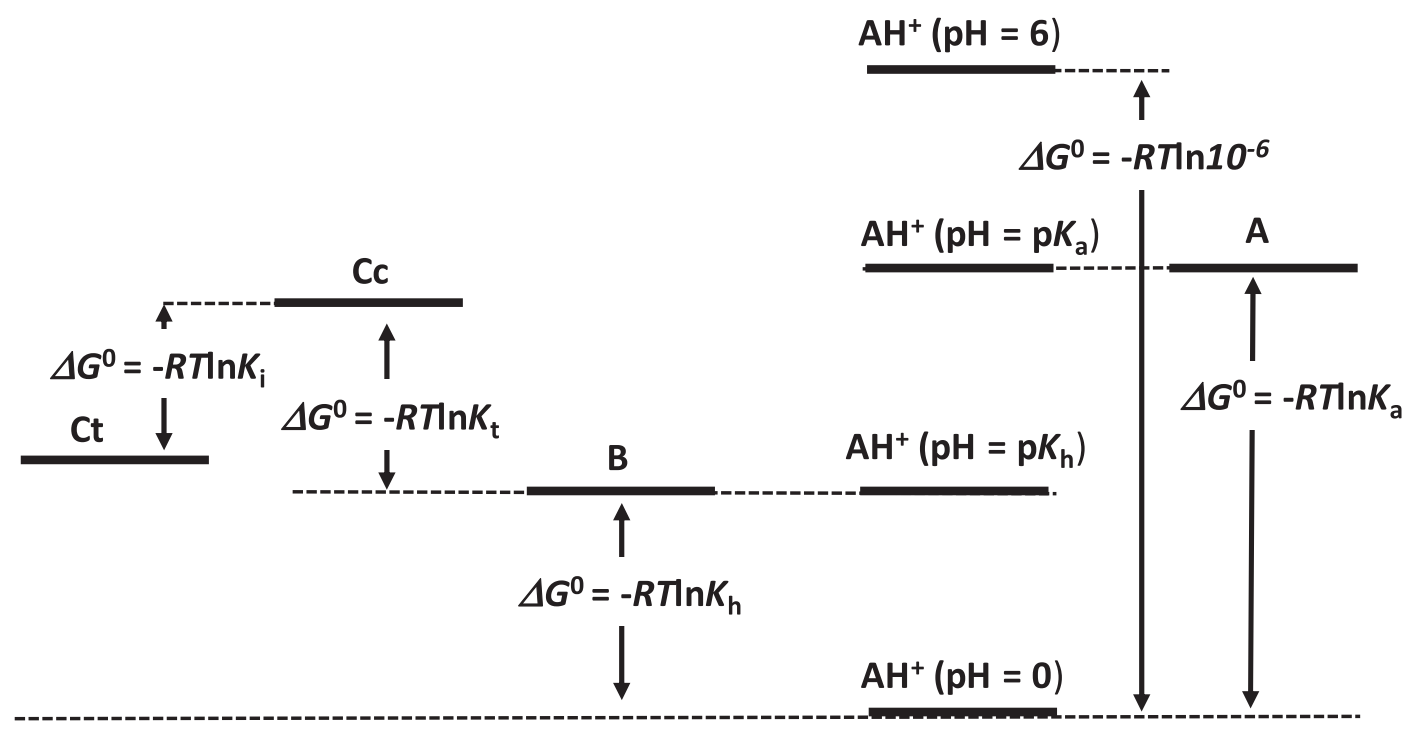

Scheme 2. Energy level diagram of a flavylium multistate at the equilibrium in acidic to moderately acidic conditions [7].

energy level diagram of 7- $\beta$-D-Glucopyranosyloxy-4'-hydroxyflavylium (GHF) in the absence [4] and presence of captisol. In particular, captisol has been tested as the best host (in comparison with other cyclodextrin derivatives) for anthocyanidins, improving storage stability and facilitating formulation [18]. The aim of this work is to investigate the effect of the host on the equilibrium and rate constants of the flavylium multistate. This knowledge could help to define new strategies of color stabilization and find more efficient flavylium-based photochromic systems.

\section{Methods}

All solutions were prepared in Millipore water. 0.2 mM GHF [19] and $0.2 \mathrm{M}$ captisol stock solutions were prepared using $0.1 \mathrm{M} \mathrm{HCl}$ and water, respectively. Any $\mathrm{pH}$ adjustment was achieved by addition of $\mathrm{HCl}, \mathrm{NaOH}$ or Theorell and Stenhagen's universal buffer, pH was recorded on a Radiometer Copenhagen PHM240 pH/ion meter (Brønshøj, Denmark). Direct pH jumps were carried out mixing stock GHF, neutralized with the same amount of $\mathrm{NaOH}$ $(0.1 \mathrm{M})$, buffer (desired $\mathrm{pH})$, stock captisol solution and water. Reverse $\mathrm{pH}$ jumps were achieved by addition of conc. $\mathrm{HCl}$ to equilibrated slightly acidic or neutral GHF + captisol solutions.

UV-Vis spectra were recorded on a Varian-Cary 100 Bio or 5000 spectrophotometer (Palo Alto, CA, USA). The stopped flow experiments were conducted on a SX20 (Applied Photophysics; Surrey, UK) spectrometer equipped with a PDA.1/UV photodiode array detector. Irradiation was carried out at $365 \mathrm{~nm}$. Quantum yields were measured based on the total absorbed light. Flash photolysis experiments were performed on a Varian Cary 5000 spectrophotometer with a Harrick fiber-mate (Pleasantville, NY, USA) coupled to an Ocean Optics 4-way cuvette holder (Dunedin, FL, USA). The compartment was isolated from daylight and a commercially Achiever 630AF camera flash (Hong Kong, China) was used as a pulsed white light source (placed in close contact with the quartz cuvette).

For host-guest association constant calculations, different concentrations of captisol solutions were used. In the case of the $\mathrm{AH}^{+}$/ captisol couple ( $\mathrm{pH} 1)$, the same procedure as for direct $\mathrm{pH}$ jumps was performed but with variations in captisol concentration (0-0.04 M). In the case of the A/captisol couple, the constant was calculated from the UV-Vis spectra recorded after a direct $\mathrm{pH}$ jump (from $\mathrm{pH} 1$ to $\mathrm{pH} 8$ ) in $2.6 \times 10^{-5} \mathrm{M}$ GHF solutions containing captisol $(0-16 \mathrm{mM})$.
Circular dichroism absorption spectra were recorded on a Chirascan qCD spectrometer (Applied Photophysics; Surrey, UK) at $298 \mathrm{~K}$ under constant nitrogen flush. The GHF concentration was kept constant $\left(6.93 \times 10^{-5} \mathrm{M}\right)$ and the captisol concentration increased from 0 to $8.33 \times 10^{-3} \mathrm{M}$. A quartz cell (optical pathlength $=1 \mathrm{~cm}$ ) was used for irradiation in the range $220-550 \mathrm{~nm}$ with an interval of $1 \mathrm{~nm}$. Two scans were averaged with baseline correction during all measurements.

Isothermal Titration Calorimetry (ITC) measurements were performed on a Nano ITC (TA Instruments; New Castle, DE, USA) with standard volumes. The solutions were thoroughly degassed before use by stirring under vacuum. The sample cell was loaded with a $0.288 \mathrm{mM}$ GHF solution $(\mathrm{pH}=6)$ and a $250 \mu$ l autopipette was filled with a $4 \mathrm{mM}$ captisol solution. GHF was titrated in a sequence of 25 injections of $10 \mu \mathrm{l}$ aliquots after achievement of baseline stability.

\section{Results and discussion}

\subsection{UV-visible spectroscopy, stopped flow and flash photolysis}

In a previous work, the equilibrium and rate constants of the GHF multistate, Scheme 1, were reported [4]. The pH-dependent absorption spectra of the pigment in the presence of $50 \mathrm{mM}$ of captisol, taken immediately after a direct $\mathrm{pH}$ jump, at pseudoequilibrium and at equilibrium, are shown in Fig. 1. The absorption spectra of Fig. 1a only reflect the flavylium-quinoidal base equilibrium, Eq. (1). Indeed, the proton transfer is very fast (complete during the mixing time of the stopped flow device), whereas the subsequent reaction (hydration) is fully negligible during the few milliseconds after the $\mathrm{pH}$ jump. The acid dissociation constant in the presence of captisol, $\mathrm{p} K_{\mathrm{a}}=4.95$, is higher than in the absence of cyclodextrin, $\mathrm{p} K_{\mathrm{a}}=5.4$, indicating that the quinoidal base binds captisol more tightly than the flavylium cation does.

As mentioned in the introduction, in the case of flavylium multistates with a high cis-trans isomerization barrier, a pseudoequilibrium involving all the species except trans-chalcone can be considered. The spectral variations at pseudo-equilibrium are represented in Fig. $1 \mathrm{~b}$ and the data fit with a single acid-base equilibrium with $\mathrm{p} \hat{K}_{\mathrm{a}}=3.25$. The higher $\mathrm{p} \hat{K}_{\mathrm{a}}$ value (4.7) in the absence of captisol [4] shows that the macrocycle has a higher affinity for $\mathrm{CB}$ (essentially, a mixture of $\mathrm{B}$ and $\mathrm{Cc}$ ) than for $\mathrm{AH}^{+}$. The 


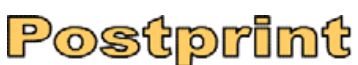

Version définitive du manuscrit publiée dans / Final version of the manuscript published in :

Dyes and Pigments (2017), Vol. 143, p. 479-487, DOI: 10.1016/j.dyepig.2017.04.061

Journal homepage : http://www.elsevier.com/locate/dyepig

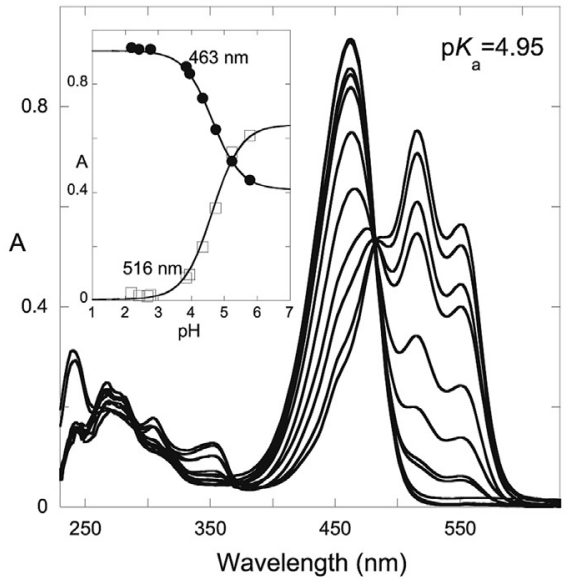

(a)

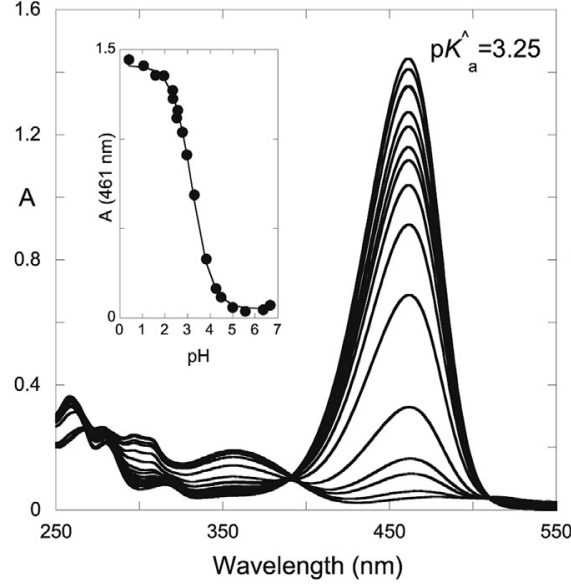

(b)

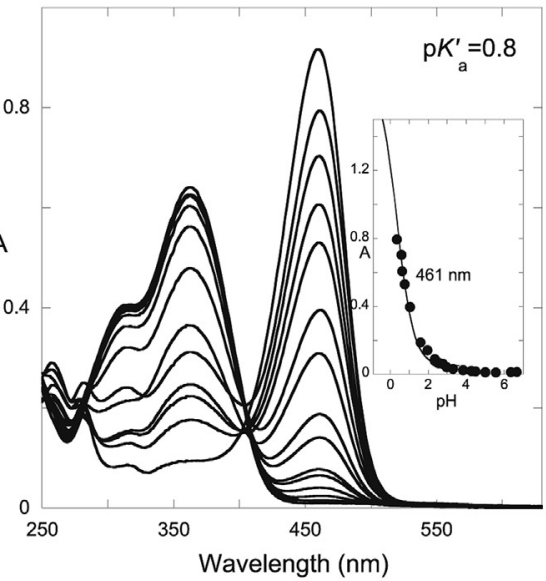

(c)

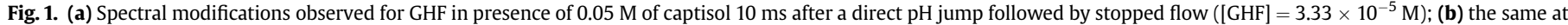

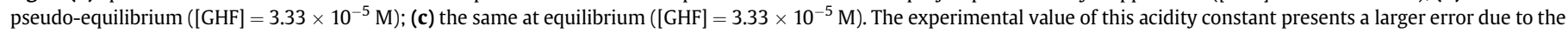

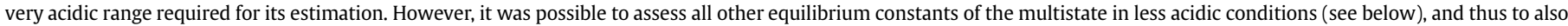
calculate the $\mathrm{p}_{\mathrm{a}}^{\prime}$ value from its definition in Eq. (9).

same trend is observed at full equilibrium, comparing $\mathrm{p} K_{\mathrm{a}}^{\prime}=0.8$ (with captisol) with $\mathrm{pK}_{\mathrm{a}}^{\prime}=2.3$ (no captisol), in this case pointing to the preferential stabilization of the trans-chalcone, Fig. 1c, a result already observed for other flavylium multistates [20]. It is especially remarkable that in the presence of captisol the flavylium ion almost behaves as a strong acid.

The $\mathrm{AH}^{+}$-captisol binding constant was estimated from spectra collected a few seconds after addition of the host at $\mathrm{pH}=1.0$. These measurements were thus carried out at pseudo-equilibrium (before significant formation of $\mathrm{Ct}$ ), where $\mathrm{AH}^{+}$is still the dominant species

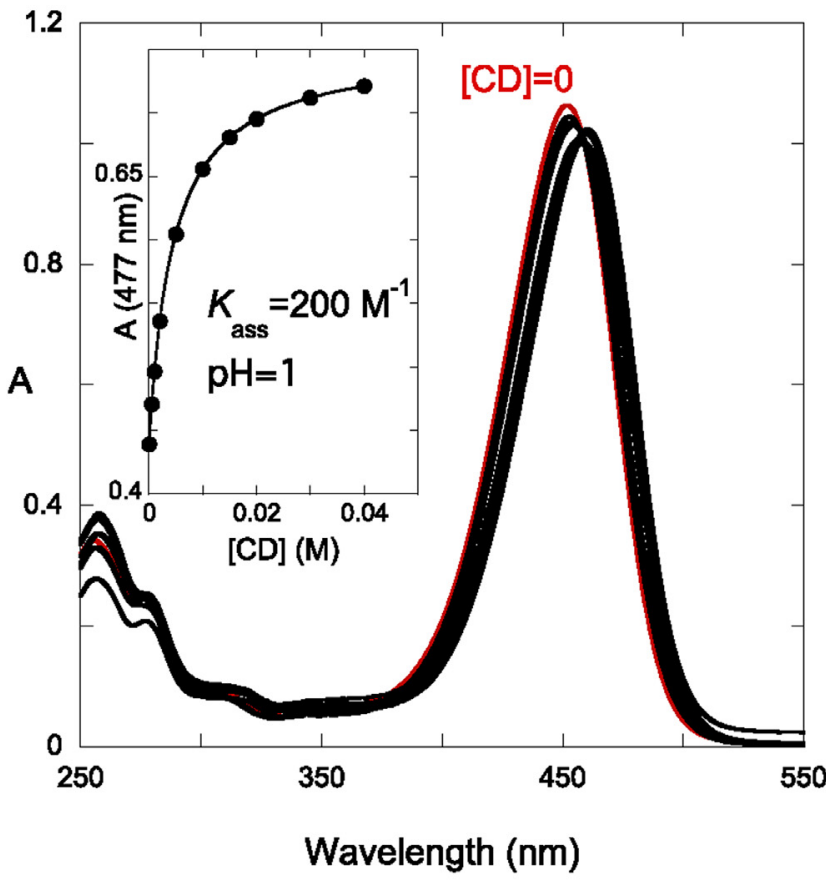

(a) at this $\mathrm{pH}$ [21]. On the other hand, the A-captisol binding was monitored by stopped flow immediately after a direct $\mathrm{pH}$ jump in the presence of captisol, see experimental part, Fig. 2. In both cases, captisol brought about significant spectral differences permitting the estimation of the corresponding binding constants from absorbance vs. captisol concentration plots. At $\mathrm{pH}=1$, the binding constant, $200 \mathrm{M}^{-1}$, is much higher than those reported with native $\beta$-cyclodextrin in similar compounds $[20,22]$. A likely explanation for this enhanced affinity is the additional electrostatic attraction between the flavylium cation and the negatively charged captisol.

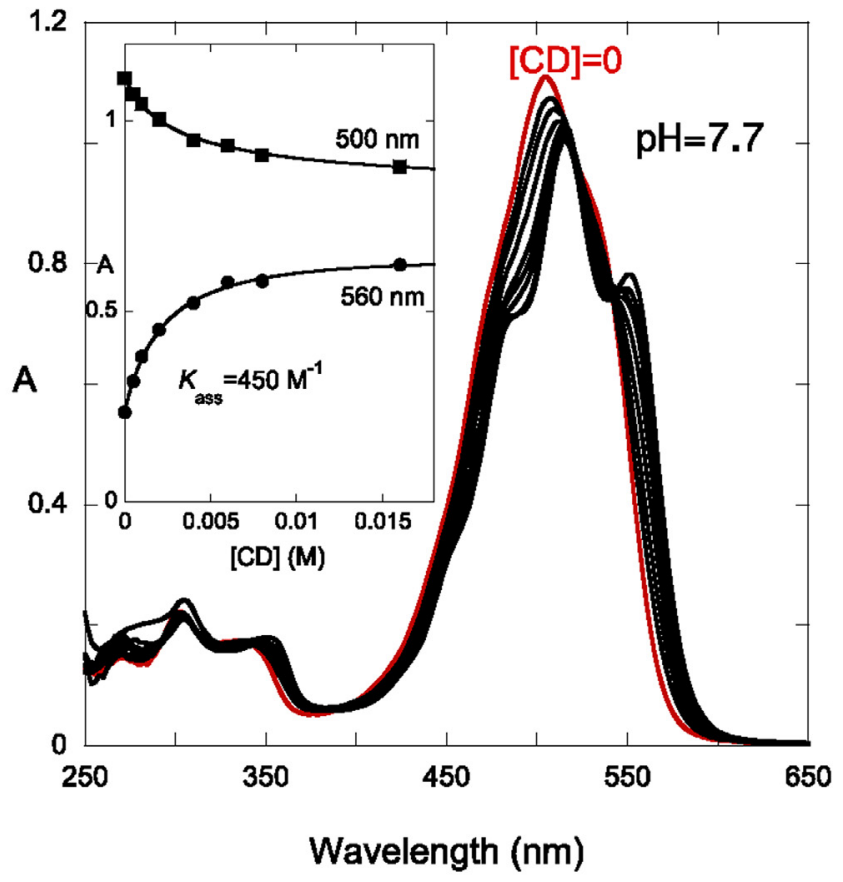

(b)

Fig. 2. (a) Spectral variations of the visible spectrum of $\mathrm{GHF} 3.3 \times 10^{-5} \mathrm{M}$ at $\mathrm{pH}=1$ as a function of added captisol; (b) the same for $\mathrm{GHF} 4 \times 10^{-5} \mathrm{M}$ at $\mathrm{pH}=7.7$ followed by stopped flow. 
Version définitive du manuscrit publiée dans / Final version of the manuscript published in :

Dyes and Pigments (2017), Vol. 143, p. 479-487, DOI: 10.1016/j.dyepig.2017.04.061

Journal homepage : http://www.elsevier.com/locate/dyepig

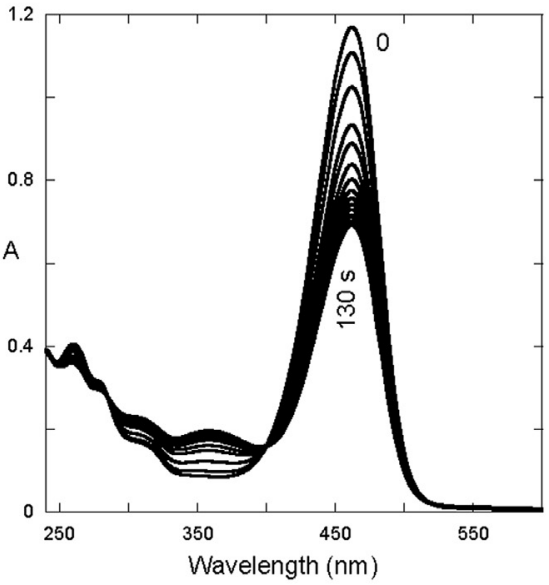

(a)

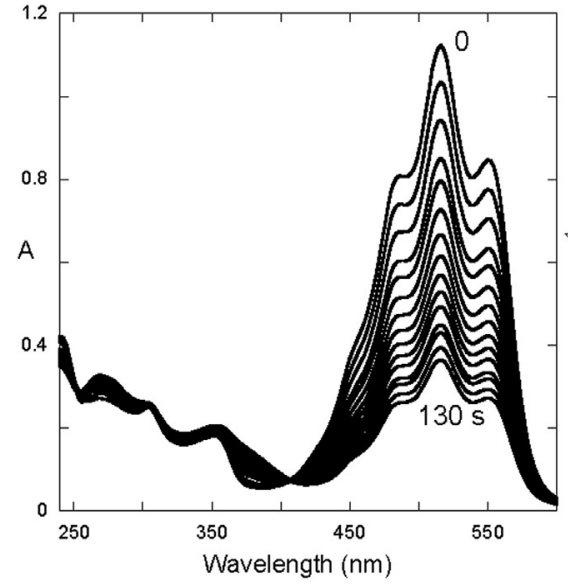

(b)

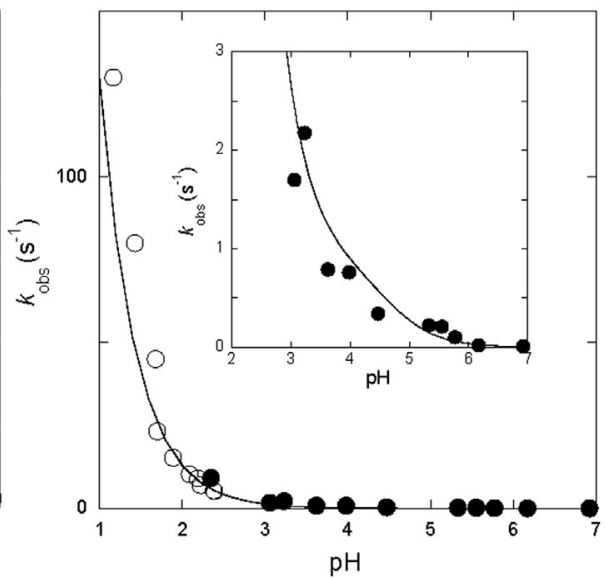

(c)

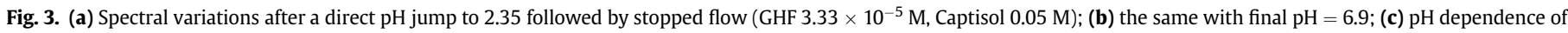

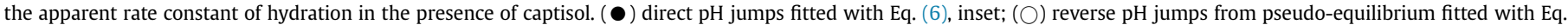
(12); Curve-fitting was achieved for the following parameters: $k_{\mathrm{h}}=0.67 \mathrm{~s}^{-1} ; k_{-\mathrm{h}} /\left(1+K_{\mathrm{t}}\right)=1.1 \times 10^{3} \mathrm{M}^{-1} \mathrm{~s}^{-1}$ and $k_{-\mathrm{h}}=1.9 \times 10^{3}$.

The quinoidal base - captisol binding constant is close to the one previously reported with $\beta$-cyclodextrin [22].

A series of direct $\mathrm{pH}$ jumps (followed by stopped flow) from equilibrated solutions at $\mathrm{pH}=1.0$ to higher $\mathrm{pH}$ values, in the presence of captisol, was carried out (Fig. 3a and b). On Fig. 3a ( $\mathrm{pH}=2.35)$, the flavylium cation disappears to give the hemiketal and cis-chalcone, the formation of trans-chalcone being much slower. At this $\mathrm{pH}$, the quinoidal base is negligible. In contrast, for a final $\mathrm{pH}=6.9$ (Fig. 3b), practically all of the flavylium cation is converted into the quinoidal base and the spectral variations refer to the disappearance of this species. Here again, no trans-chalcone is formed. At high $\mathrm{pH}$ values, the fraction of electrophilic $\mathrm{AH}^{+}$(the sole species undergoing water addition) is weak and hydration is slower than tautomerization and rate-determining, see Eq. (6).

Finally, the system reaches the equilibrium through a slower process yielding the trans-chalcone, as shown in Fig. 4 for a direct $\mathrm{pH}$ jump to $\mathrm{pH}=2.8$. A plot of the isomerization rate constants as a function of $\mathrm{pH}$ gives the expected sigmoid curve (Eq. (7)), with an inflexion point at $\mathrm{p} \hat{K}_{\mathrm{a}}=3.2$, in agreement with the previous estimation (Fig. 1b). Moreover, the two well defined limits of this curve at low and higher $\mathrm{pH}$ values leads respectively to $k_{-\mathrm{i}}=6 \times 10^{-6} \mathrm{~s}^{-1}$ and $K_{\mathrm{h}} K_{\mathrm{t}} k_{\mathrm{i}} / K_{\mathrm{a}}=1.4 \times 10^{-3} \mathrm{~s}^{-1}$.

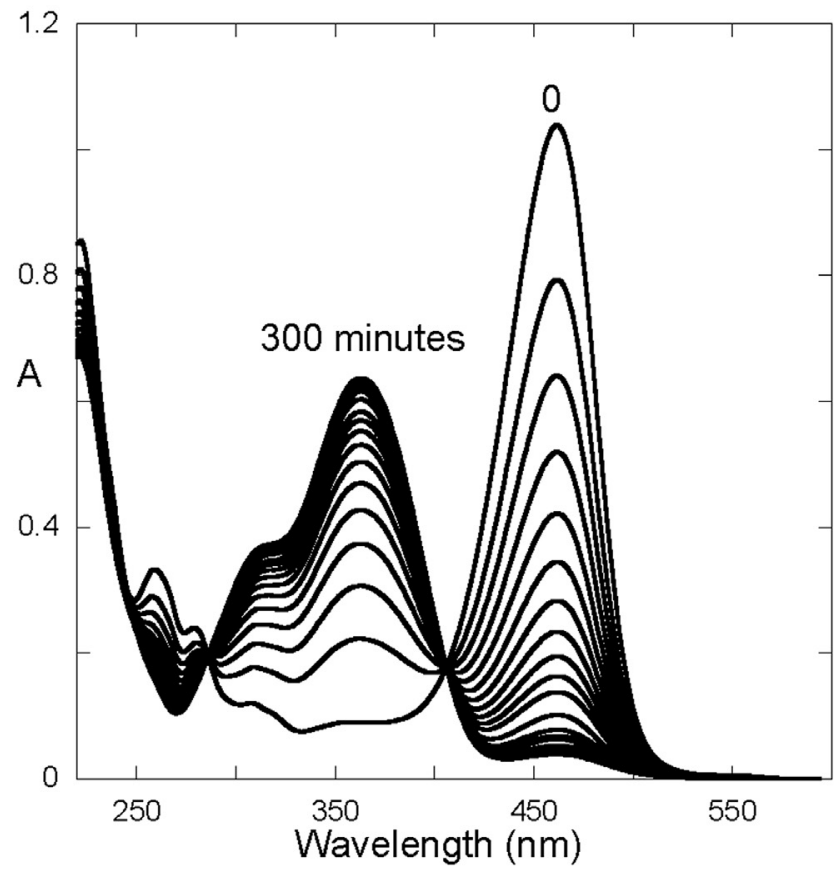

(a)

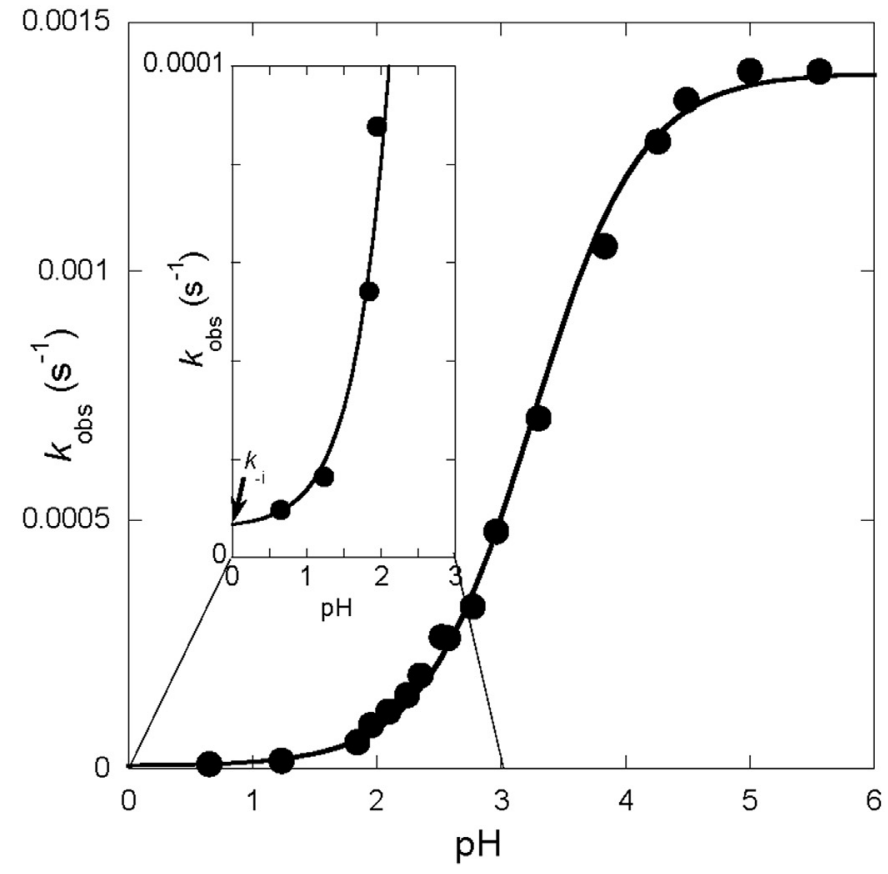

(b)

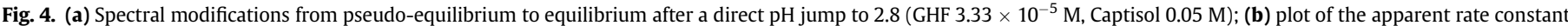

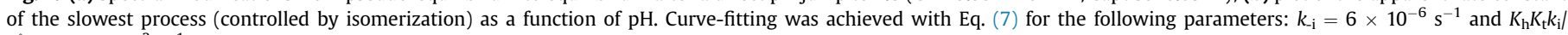
$K_{\mathrm{a}}=1.4 \times 10^{-3} \mathrm{~s}^{-1}$ 
Version définitive du manuscrit publiée dans / Final version of the manuscript published in :

Dyes and Pigments (2017), Vol. 143, p. 479-487, DOI: 10.1016/j.dyepig.2017.04.061

Journal homepage : http://www.elsevier.com/locate/dyepig

Table 1

Kinetic and thermodynamic parameters obtained experimentally from Figs. 1 and 3-5.

\begin{tabular}{|c|c|c|c|c|c|c|c|}
\hline$K_{\mathrm{a}}^{\wedge}$ & $K_{\mathrm{a}}$ & $k_{\text {-h }} /\left(1+K_{\mathrm{t}}\right)$ & $k_{\mathrm{h}}$ & $K_{\mathrm{h}} K_{\mathrm{t}} k_{\mathrm{i}} / K_{\mathrm{a}}$ & $k_{-\mathrm{i}}$ & $k_{-t}$ & $K_{t}$ \\
\hline $10^{-3.25}$ & $10^{-4.95}$ & $1.1 \times 10^{3} \mathrm{M}^{-1} \mathrm{~s}^{-1}$ & $0.67 \mathrm{~s}^{-1}$ & $1.4 \times 10^{-3} \mathrm{~s}^{-1}$ & $6 \times 10^{-6} s^{-1}$ & $0.025 \mathrm{~s}^{-1}$ & 0.74 \\
\hline
\end{tabular}

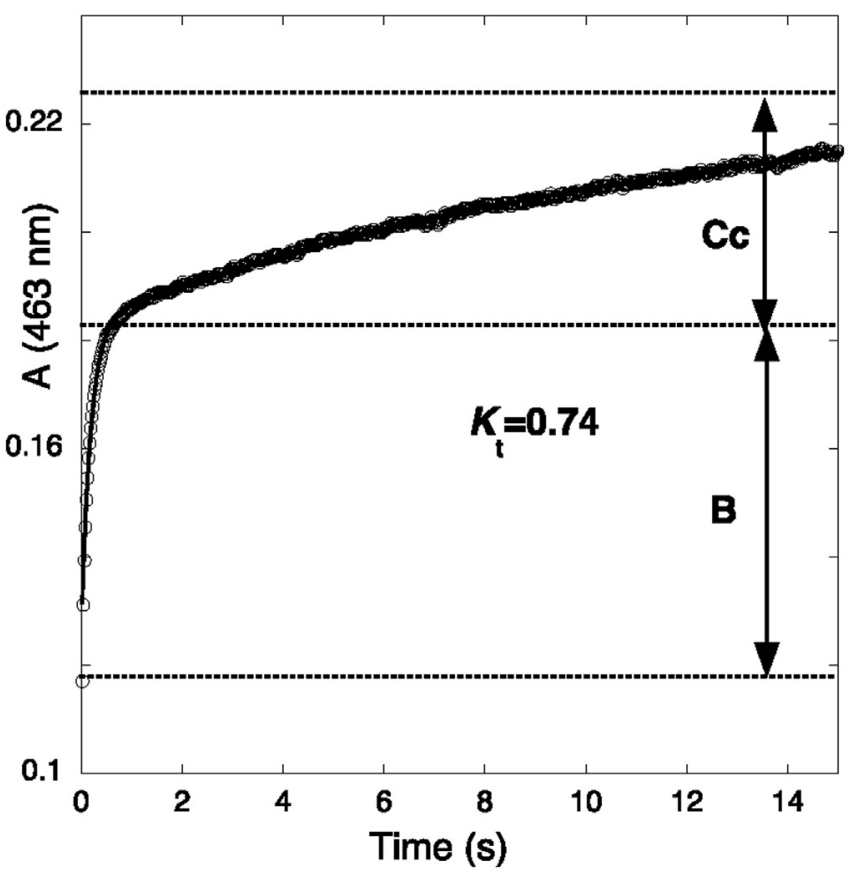

Fig. 5. Reverse $\mathrm{pH}$ jump from a solution at pseudo equilibrium $(\mathrm{pH}=6.0)$ to $\mathrm{pH}=2.4$ followed by stopped flow. The first process is due to hydration, Eq. (12), and the second to tautomerization, Eq. (13).
Table 1 summarizes the kinetic and thermodynamic parameters obtained experimentally from Figs. 1, 3 and 4.

The coherence of these data can be tested considering that the value of $K_{\mathrm{h}}\left(1+K_{\mathrm{t}}\right)$ obtained from $\hat{K_{\mathrm{a}}}-K_{\mathrm{a}}$ is equal to the ratio between column 4 and column 3 in Table $1\left(6.1 \times 10^{-4}\right)$.

In order to obtain all the rate and equilibrium constants, one more relation is necessary. When the flavylium multistate exhibits a cis-trans isomerization barrier, it is possible to carry out a reverse $\mathrm{pH}$ jump from the pseudo-equilibrium to acidic $\mathrm{pH}$ values, Fig. 5 $[3,23]$.

The use of reverse $\mathrm{pH}$ jumps was reported by McClelland and co-workers $[3,23]$. When the final $\mathrm{pH}$ is sufficiently acidic, the hydration step, due to its dependence on $\left[\mathrm{H}^{+}\right]$, becomes faster than tautomerization, the so-called change of regime. Consequently the equilibrium between $\mathrm{B}$ and $\mathrm{Cc}$ is disrupted, $\mathrm{B}$ disappears to give $\mathrm{AH}^{+}$in a first kinetic step, according to Eq. (12), followed by a slower reaction that converts $\mathrm{Cc}$ in more flavylium cation via $\mathrm{B}$, Eq. (13). The $\mathrm{pH}$ dependence of the faster observed rate constant is represented in Fig. 3c (open circles). Curve-fitting was achieved with the parameters reported in Table 1.

In the flash photolysis experiments (Fig. 6), the trans-chalcone is excited and converted into cis-chalcone during the lifetime of the flash ( $\mu \mathrm{s}$ ), as shown by the bleaching at $362 \mathrm{~nm}$, a wavelength where $\mathrm{Cc}$ is expected to absorb less than $\mathrm{Ct}[6,23]$. Considering that hydration is faster than tautomerization at very acidic $\mathrm{pH}$ values, the rate-determining step should be the tautomerization reaction, as observed in Fig. 5.

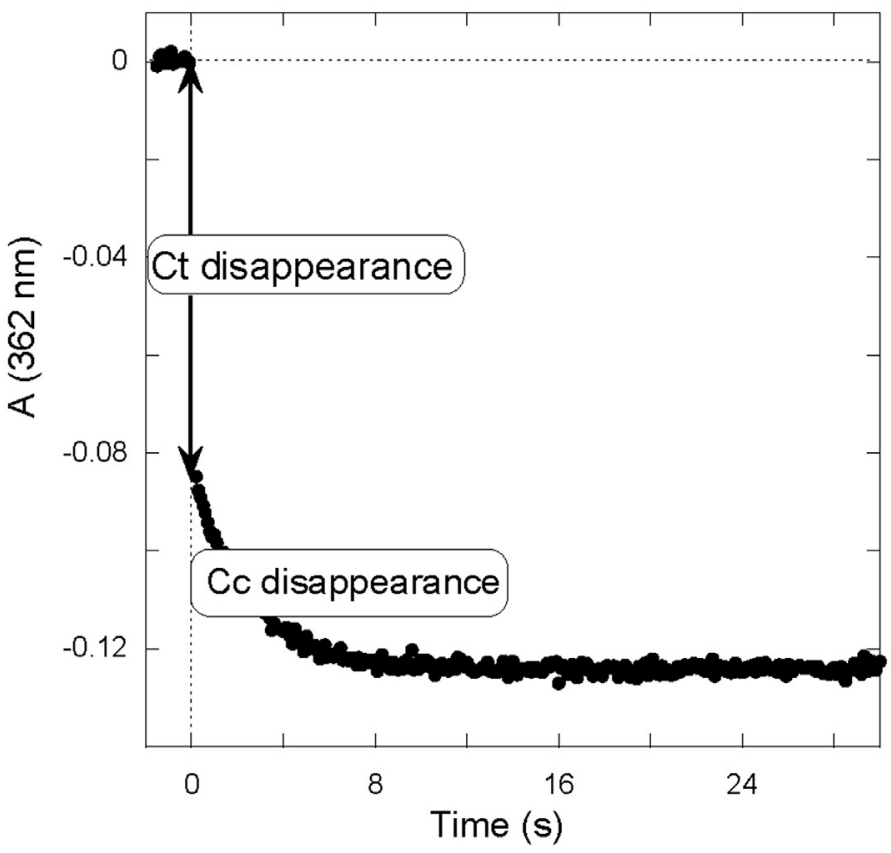

(a)

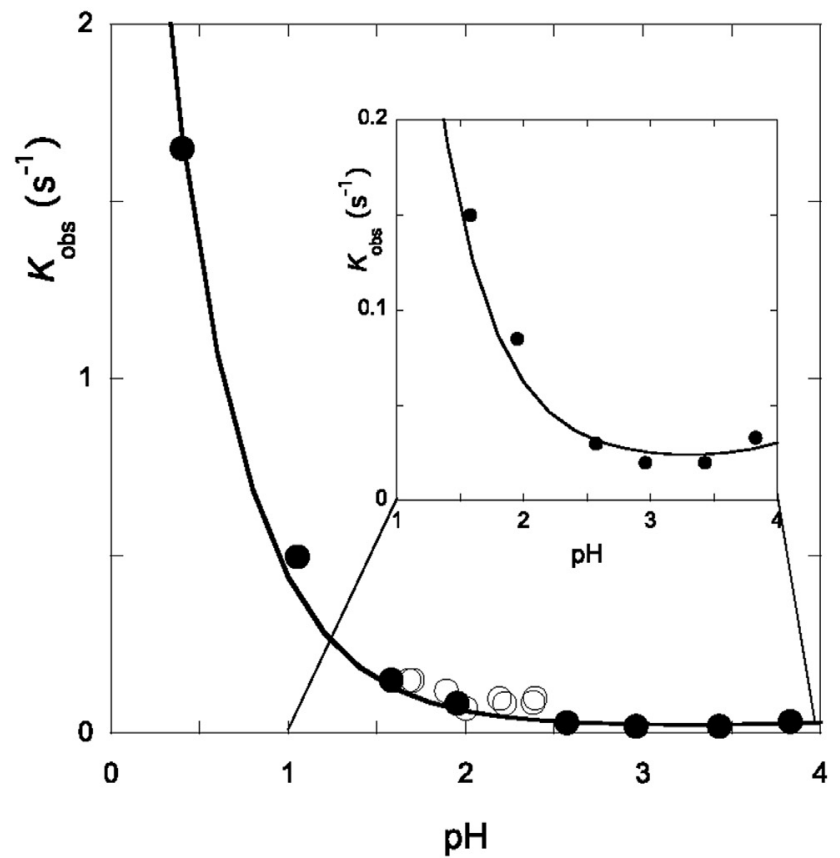

(b)

Fig. 6. (a) Time dependence of $\mathrm{A}(362 \mathrm{~nm})$ (absorption of chalcones) after a light flash at $\mathrm{pH}=1.05$; (b( $\bullet$ ) Curve-fitting was achieved according to Eq. (13) for $k_{-\mathrm{t}}=0.02 \mathrm{~s}^{-1}$ and $k$. $\mathrm{t}^{\mathrm{H}}=4.2 \mathrm{M}^{-1} \mathrm{~s}^{-1} ;(\bigcirc)$ data from the slowest process in Fig. 5. 
Version définitive du manuscrit publiée dans / Final version of the manuscript published in :

Dyes and Pigments (2017), Vol. 143, p. 479-487, DOI: 10.1016/j.dyepig.2017.04.061

Journal homepage : http://www.elsevier.com/locate/dyepig

Table 2

Equilibrium and rate constants of GHF in the absence and presence of captisol (50 mM).

\begin{tabular}{|c|c|c|c|c|c|c|}
\hline Compound & $\mathrm{p} K_{\mathrm{a}}^{\prime}$ & $\mathrm{p} K_{\mathrm{a}}$ & $\mathrm{p} K_{\mathrm{a}}$ & $K_{\mathrm{h}} / \mathrm{M}$ & $K_{\mathrm{t}}^{1}$ & $K_{\mathrm{i}}^{1}$ \\
\hline GHF & $2.30 \pm 0.05$ & $4.70 \pm 0.05$ & $5.40 \pm 0.05$ & $8.9 \times 10^{-6}$ & 0.60 & 935 \\
\hline \multirow[t]{2}{*}{ GHF + Captisol } & $0.83 \pm 0.10$ & $3.25 \pm 0.05$ & $4.95 \pm 0.05$ & $3.5 \times 10^{-4}$ & 0.74 & 567 \\
\hline & $\boldsymbol{k}_{\mathrm{h}} / \mathbf{s}^{-1 \mathrm{a}}$ & $\boldsymbol{k}_{-\mathrm{h}} / \mathbf{M}^{-1} \mathbf{s}^{-1 \mathrm{a}}$ & $\boldsymbol{k}_{\mathrm{t}} / \mathbf{s}^{-1}$ & $\boldsymbol{k}_{-\mathrm{t}} / \mathbf{s}^{-1 \mathrm{a}}$ & $\boldsymbol{k}_{\mathrm{i}} / \mathbf{s}^{-1 \mathrm{a}}$ & $\boldsymbol{k}_{-\mathrm{i}} / \mathbf{s}^{-1 \mathrm{a}}$ \\
\hline GHF & 0.08 & $9 \times 10^{3}$ & 0.36 & 0.60 & $5.5 \times 10^{-3}$ & $5.9 \times 10^{-6}$ \\
\hline GHF + Captisol ${ }^{a}$ & 0.67 & $1.9 \times 10^{3}$ & 0.019 & 0.025 & $3.4 \times 10^{-3}$ & $6 \times 10^{-6}$ \\
\hline
\end{tabular}

a Estimated error: $10 \%$.

The two sets of experimental data regarding the slowest process in Fig. 5 and the one of Fig. 6, express the same trend, confirming that both kinetic steps refer to the tautomerization reaction. The relatively small differences observed in Fig. 6b, may be attributed to chalcone photochromism brought about by the very intense lamp used for analysis in the stopped flow apparatus. Such interferences do not occur in the flash photolysis experiments as analysis is carried out by a standard spectrophotometer.

The data reported in Table 1 permit to calculate all the rate and equilibrium constants presented in Table 2.

Inspection of Table 2 allow to emphasize some properties of the multistate in the presence of captisol. The thermodynamic constant of hydration increases ca. 39 times due to the increase of the hydration rate constant and decrease of the dehydration rate constant. Although the other equilibrium constants are only modestly affected by captisol, this is not the case for the tautomerization rate constants, showing that it is more difficult to open and close the ring in the presence of the host. The decrease of the ring-opening/ ring-closure rate constants can be explained by the geometric constrains brought about by the host. However, such constrains do not seem to operate in the isomerization. We still do not have a reliable interpretation for this behavior.

Similarly to other flavylium-based systems, irradiation of the trans-chalcone leads to reversible formation of the flavylium cation/quinoidal base pair (Fig. 7). The photochromic system in the presence of captisol can operate at low $\mathrm{pH}$ values, gives a sharp color contrast and possesses a quantum yield $(\phi=0.3)$ that is three times higher than in the absence of the host $(\phi=0.1)$.

\subsection{Isothermal titration calorimetry (ITC)}

The isothermal titration calorimetry of GHF by captisol (Fig. 8) was carried out from an equilibrated GHF solution at $\mathrm{pH}=6.18$, i.e. under conditions where the trans-chalcone is essentially the sole species in solution. The method permits the calculation of the thermodynamic parameters of $\mathrm{Ct}-$ captisol binding: $K_{b}=7700 \mathrm{M}^{-1}, \Delta H_{b}^{0}=-21.6 \mathrm{~kJ} \mathrm{~mol}^{-1}, \Delta S_{b}^{0}=+4.83 \mathrm{~J} \mathrm{~mol}^{-1} \mathrm{~K}^{-1}$. The binding is essentially driven by a favorable (exothermic) enthalpic contribution. However, the weakly positive (favorable) entropic term suggests that the reduction in the degrees of freedom of both partners when they associate $\left(\Delta S^{0}<0\right)$ is largely compensated by their concomitant relative desolvation (hydrophobic effect, $\Delta S^{0}>0$ ). The $K_{b}$ value was used to superimpose (calibrate) the two energy level diagrams in the absence and presence of the host, see Scheme 3.

\subsection{Circular dichroism}

When a chiral transparent compound binds an achiral UV-Vis absorbing molecule, thereby causing a perturbation of its transition dipole moment, an induced circular dichroism (ICD) signal can

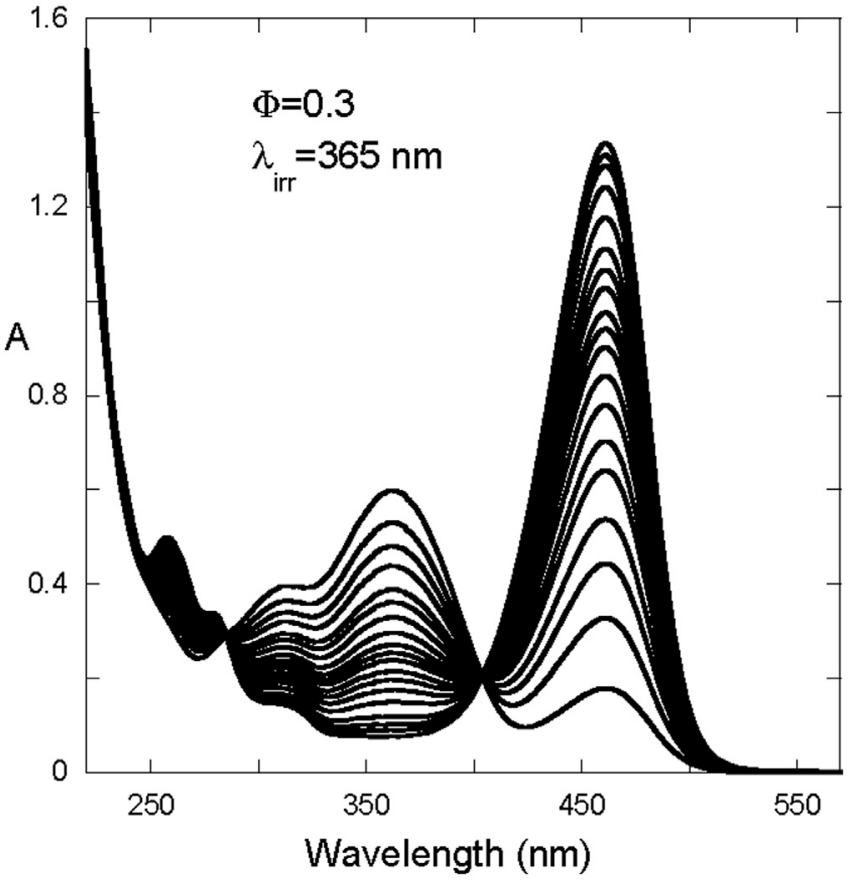

Fig. 7. Spectral modifications of GHF $\left(3.5 \times 10^{-5} \mathrm{M}\right)$ upon irradiation at $365 \mathrm{~nm}$ in the presence of captisol $(50 \mathrm{mM})$ at $\mathrm{pH}=1.95$.

form [24]. Such signals have been observed with host-guest complexes, e.g. with the inclusion complex of a trans-chalcone in $\beta$ cyclodextrin $[25,26]$. Fig. 9 shows the circular dichroism spectra of $\mathrm{GHF}$ at $\mathrm{pH}=6.0$ as a function of captisol concentration. The CD spectra can be attributed to the chiral trans-chalcone - captisol complex. The ICD signal permits the evaluation of the corresponding binding constant, through a fitting of the maximal ellipticity as a function of the host concentration assuming a $1: 1$ binding model: $K_{\mathrm{b}}=8 \times 10^{3} \mathrm{M}^{-1}$. This value is in good agreement with the one assessed by ITC (Fig. 8).

Taking into account the equilibrium constants of Table 1, it is possible to draw an energy level diagram of GHF in the absence (black) and presence (red) of captisol. The two independently constructed diagrams can be merged and correctly positioned to each other, owing to the experimental free energy of $\mathrm{Ct}$ - captisol binding, $\Delta G^{0}=-\mathrm{RT} \ln K_{\mathrm{b}}\left(K_{\mathrm{b}}\right.$ value assessed by ITC, confirmed by ICD, Table 2). The association constants to captisol of all other species can thus obtained by simply calculating the corresponding $\Delta G^{0}$ values (blue). It is satisfactory to note that the binding free energies of the quinoidal base and flavylium cation deduced from the independently determined binding constants (Fig. 2) are in reasonable agreement with the theoretical values 
Version définitive du manuscrit publiée dans / Final version of the manuscript published in :

Dyes and Pigments (2017), Vol. 143, p. 479-487, DOI: 10.1016/j.dyepig.2017.04.061

Journal homepage : http://www.elsevier.com/locate/dyepig

Time (min)
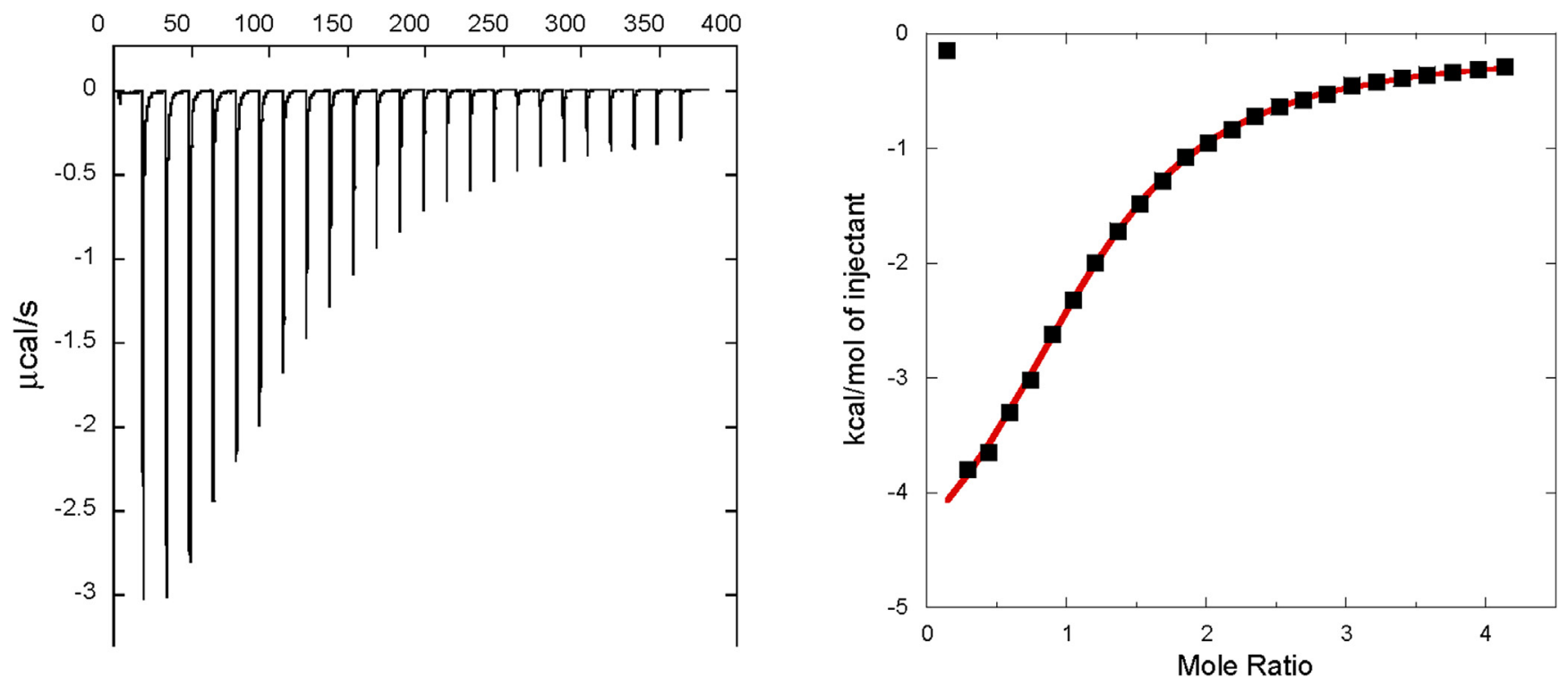

Fig. 8. Isothermal titration calorimetry of $\mathrm{GHF}(0.288 \mathrm{mM})$ by captisol $(4 \mathrm{mM})$ at $\mathrm{pH}=6.18$.

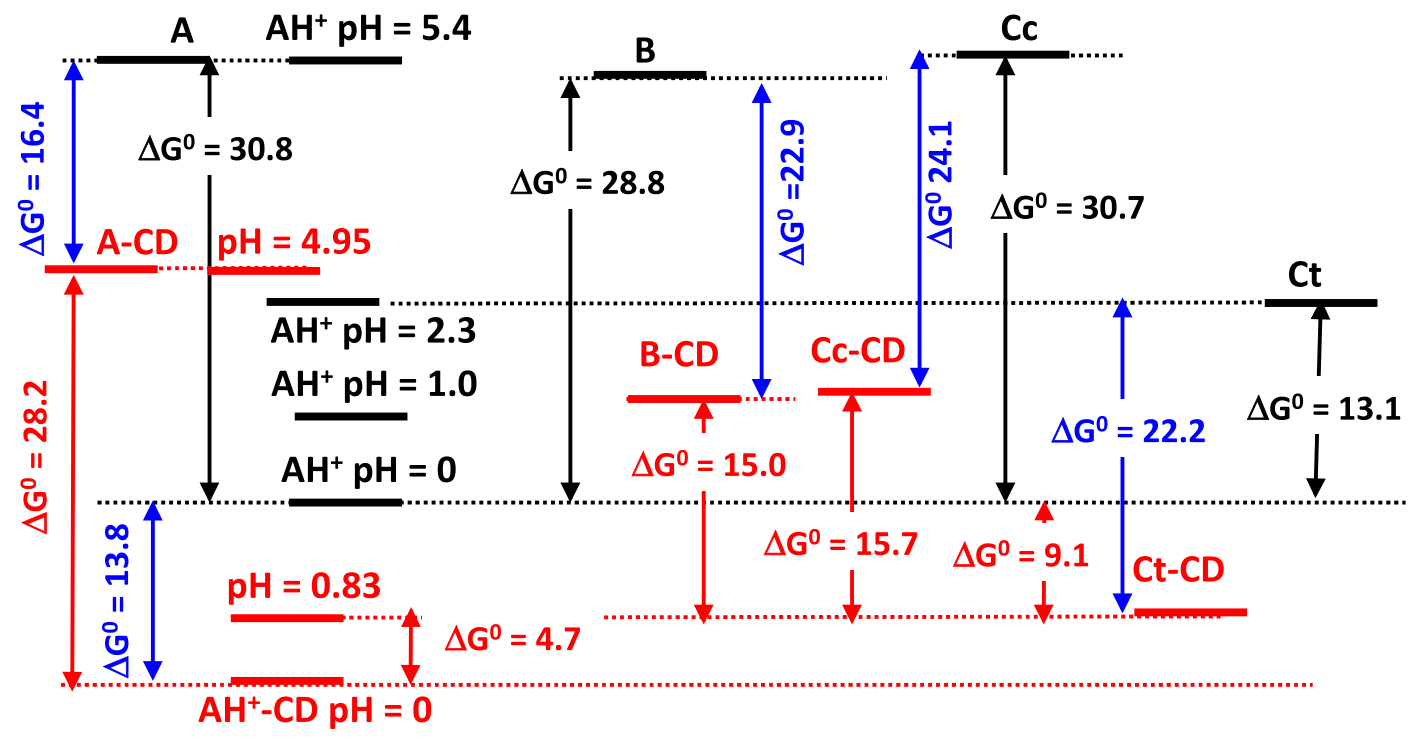

$\Delta \mathbf{G}^{0} / \mathrm{kJmol}^{-1}$

Scheme 3. Energy level diagram of GHF in the absence (black) and presence of $50 \mathrm{mM}$ captisol (red). Superposition of the two diagrams using the trans-chalcone - captisol binding constant allows the calculation of all binding constants (blue color).

calculated from the diagram. In particular, Scheme 3 is very useful to calculate the binding constants of the elusive species $\mathrm{B}$ and Cc.

The different $K_{\mathrm{b}}$ values (Table 3 ) show that the rigid tricyclic chromophores of the flavylium cation and quinoidal base have little affinity for captisol, probably because of steric hindrance. The distortions brought about by water addition (non-planar C-ring) and subsequent tautomerization (C-ring opening) strength the binding by one order of magnitude.

\section{Conclusions}

Cyclodextrins can modify the pH-dependent mole fraction distribution of the flavylium multistate, in particular by shifting the $\mathrm{pH}$ domain of trans-chalcone prevalence toward low $\mathrm{pH}$ values, where in general the stability of the multistate species is higher. Of interest is the 3-fold increase in photochromism efficiency in the presence of captisol. The superimposition of the energy level diagrams in the absence and presence of the host permits the calculation of the 
Version définitive du manuscrit publiée dans / Final version of the manuscript published in :

Dyes and Pigments (2017), Vol. 143, p. 479-487, DOI: 10.1016/j.dyepig.2017.04.061

Journal homepage : http://www.elsevier.com/locate/dyepig

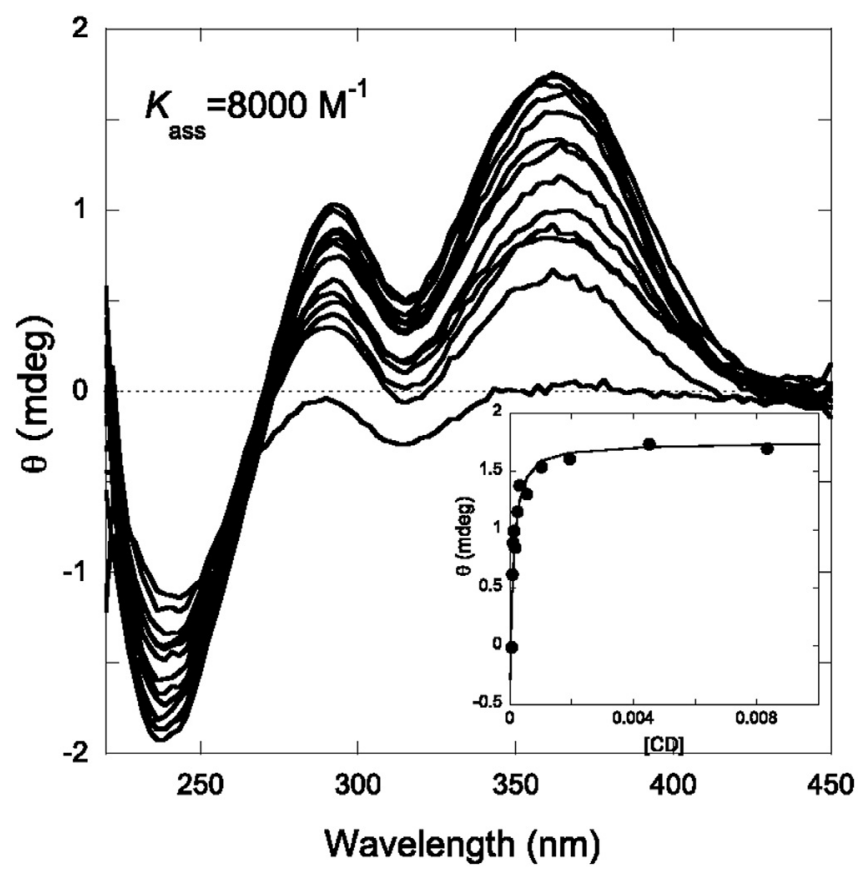

Fig. 9. Circular dichroism spectra of GHF $\left(6.93 \times 10^{-5} \mathrm{M}\right)$ as a function of captisol concentration $\left(0-8.33 \times 10^{-3} \mathrm{M}\right), \mathrm{pH}=6.0$.

Table 3

Association constants of GHF with captisol. ${ }^{a}$

\begin{tabular}{llllll}
\hline & $\mathrm{AH}^{+}$ & $\mathrm{A}$ & $\mathrm{B}$ & $\mathrm{Cc}$ & $\mathrm{Ct}$ \\
\hline$K_{b}\left(\mathrm{M}^{-1}\right)^{\mathrm{b}}$ & 200 & 450 & $(10300)$ & $(17000)$ & $8000^{\mathrm{c}}$ \\
$\Delta \mathrm{G}^{0 \mathrm{~b}}\left(\mathrm{~kJ} \cdot \mathrm{mol}^{-1}\right)$ & $13.1(13.8)$ & $15.1(16.4)$ & $(22.9)$ & $(24.1)$ & $22.2^{\mathrm{c}}$ \\
\hline
\end{tabular}

a Estimated error: $10 \%$.

b Experimental values; between parentheses: calculated values.

c Used to calibrate the system (determined by UV-Vis; CD and ITC).

association constants of all the multistate species, provided that one of these constants is assessed by an appropriate experimental method. This general approach can be applied to any other types of 1:1 binding involving the flavylium multistate.

\section{Acknowledgements}

This work was supported by the Associated Laboratory for Sustainable Chemistry - Clean Processes and Technologies - LAQV. The latter is financed by national funds from FCT/MEC (UID/QUI/ 50006/2013) and co-financed by the ERDF under the PT2020 Partnership Agreement (POCI-01-0145- FEDER-007265). FCT/MEC is also acknowledged through the Projects PTDC/QEQ-QFI/1971/ 2014. J.M. is grateful for a doctoral grant from CONACYT (MEX/ Ref. 288188); N.B. gratefully acknowledges a postdoctoral grant from FCT/MEC (SFRH/BPD/84805/2012). We are grateful to Dr. Sofia Pauleta for allowing us to use the Isothermal Titration Calorimeter (FCT-ANR/BBB-MET/0023/2012) and to Dr. Cecília Bonifacio for technical assistance with the ITC experiments.

\section{References}

[1] Brouillard R, Dubois J-E. Mechanism of the structural transformations of anthocyanins in acidic media. J Am Chem Soc 1977;99(5):1359-64.

[2] Brouillard R, Lang J. The hemiacetal-cis-chalcone equilibrium of malvin, a natural anthocyanin. Can J Chem 1990;68(5):755-61.

[3] McClelland RA, Gedge S. Hydration of the flavylium ion. J Am Chem Soc 1980;102(18):5838-48.

[4] Basílio N, Al Bittar S, Mora N, Dangles O, Pina F. Analogs of natural 3deoxyanthocyanins: O-Glucosides of the 4, 7-dihydroxyflavylium ion and the deep influence of glycosidation on color. Int J Mol Sci 2016;17(10):1751.

[5] Petrov V, Gavara R, Dangles O, Al Bittar S, Mora-Soumille N, Pina F. A flash photolysis and stopped-flow spectroscopy study of $3^{\prime}, 4^{\prime}$-dihydroxy-7-O- $\beta$-dglucopyranosyloxyflavylium chloride, an anthocyanin analogue exhibiting efficient photochromic properties. Photoch Photobio Sci 2013;12(3):576-81.

[6] Pina F, Melo MJ, Laia CA, Parola AJ, Lima JC. Chemistry and applications of flavylium compounds: a handful of colours. Chem Socy Rev 2012;41(2): 869-908.

[7] Basílio N, Pina F. Chemistry and photochemistry of anthocyanins and related compounds: a thermodynamic and kinetic approach. Molecules 2016;21(11): 1502.

[8] Harada T, Pham D-T, Leung MH, Ngo HT, Lincoln SF, Easton CJ, et al. Cooperative binding and stabilization of the medicinal pigment curcumin by diamide linked $\gamma$-cyclodextrin dimers: a spectroscopic characterization. J Phys Chem B 2010;115(5):1268-74.

[9] Jeong S, Kang WY, Song CK, Park JS. Supramolecular cyclodextrin-dye complex exhibiting selective and efficient quenching by lead ions. Dyes Pigments 2012;93(1):1544-8.

[10] Singh M, Pal H, Koti A, Sapre A. Photophysical properties and rotational relaxation dynamics of neutral red bound to $\beta$-cyclodextrin. J Phys Chem A 2004;108(9):1465-74.

[11] Szente L, Szejtli J. Highly soluble cyclodextrin derivatives: chemistry, properties, and trends in development. Adv Drug Deliv Rev 1999;36(1):17-28.

[12] Tønnesen HH, Másson M, Loftsson T. Studies of curcumin and curcuminoids. XXVII. Cyclodextrin complexation: solubility, chemical and photochemical stability. Int J Pharm 2002;244(1):127-35.

[13] Al Hagbani T, Nazzal S. Curcumin complexation with cyclodextrins by the autoclave process: method development and characterization of complex formation. Int J Pharm 2017;520(1-2):173-80.

[14] Lockwood SF, O'Malley S, Mosher GL. Improved aqueous solubility of crystalline astaxanthin ( $3,3^{\prime}$-dihydroxy- $\beta, \beta$-carotene- $4,4^{\prime}$-dione) by Captisol $^{\circledR}$ (sulfobutyl ether $\beta$-cyclodextrin). J Pharm Sci 2003;92(4):922-6.

[15] Háda M, Nagy V, Deli J, Agócs A. Hydrophilic carotenoids: recent progress. Molecules 2012;17(5):5003-12.

[16] Kulkarni AD, Belgamwar VS. Inclusion complex of chrysin with sulfobutyl

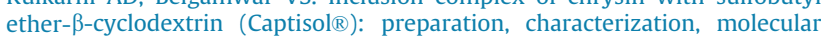
modelling and in vitro anticancer activity. J Mol Struct 2017:1128:563-71.

[17] Jullian C, Moyano L, Yanez C, Olea-Azar C. Complexation of quercetin with three kinds of cyclodextrins: an antioxidant study. Spectrochim Acta A-M 2007;67(1):230-4.

[18] Roewer N, Broscheit J. Anthocyanidin complex for the treatment of multiple myeloma. Sapiotec Gmbh. US20150258202 A1. US 14/432,654. 2015. A61K47/ 48, A61K45/06, A61K31/724 ed2015.

[19] Al Bittar S, Mora N, Loonis M, Dangles O. A simple synthesis of 3deoxyanthocyanidins and their O-glucosides. Tetrahedron 2016;72(29): 4294-302.

[20] Petrov V, Stanimirov S, Petrov IK, Fernandes A, de Freitas V, Pina F. Emptying the $\beta$-cyclodextrin cavity by light: photochemical removal of the transchalcone of 4', 7-dihydroxyflavylium. J Phys Chem A 2013;117(41): 10692-701.

[21] At the pseudo equilibrium $\left(\mathrm{pK}^{\wedge} \mathrm{a}=3.25\right)$ and $\mathrm{pH}=1$, the trans-chalcone is the dominant species.

[22] Basílio N, Fernandes A, de Freitas V, Gago S, Pina F. Effect of $\beta$-cyclodextrin on the chemistry of 3', 4', 7-trihydroxyflavylium. New J Chem 2013;37(10): 3166-73.

[23] McClelland RA, McGall GH. Hydration of the flavylium ion. 2. The 4'hydroxyflavylium ion. J Org Chem 1982;47(19):3730-6.

[24] Allenmark S. Induced circular dichroism by chiral molecular interaction. Chirality 2003;15(5):409-22.

[25] Zhang X, Gramlich G, Wang X, Nau WM. A joint structural, kinetic, and thermodynamic investigation of substituent effects on Host- guest complexation of bicyclic azoalkanes by $\beta$-cyclodextrin. J Am Chem Soc 2002;124(2):254-63.

[26] Gago S, Basílio N, Fernandes A, Freitas V, Quintas A, Pina F. Photochromism of the complex between 4'-(2-hydroxyethoxy)-7-hydroxyflavylium and $\beta$ cyclodextrin, studied by $1 \mathrm{H}$ NMR, UV-Vis, continuous irradiation and circular dichroism. Dyes Pigments 2014;110:106-12. 